\title{
(t)
}

\section{AS LUTAS URBANAS E O PAPEL DOS PARTIDOS POLÍTICOS}

\author{
URBAN STRUGGLES AND THE ROLE OF POLITICAL PARTIES
}

\section{Isabela Ramos Ribeiro'}

\section{RESUMO}

O presente artigo procura relacionar as lutas sociais urbanas, em especial as recentes manifestações de junho, com o papel dos partidos políticos no Brasil atualmente. Tem como objetivo demonstrar a importância da organização política tanto para a conquista de direitos como para a superação do capitalismo. Para tal, serão abordadas algumas concepções teóricas de partido, em uma análise bibliográfica, buscando trazer contribuições para pensar a organização política de forma coerente com as condições e determinantes sócio-históricas particulares em nosso país. Se, conforme as concepções de Lenin e Gramsci, o partido deve mediar a luta cotidiana com a luta mais ampla, sendo um agente na construção da vontade nacional-popular e de uma nova hegemonia, deparamo-nos hoje com o desafio de superar o apartidarismo e o antipartidarismo presentes no senso comum. Para tanto, é tarefa imprescindível entender esse momento histórico e suas consequências para a luta de classes nas cidades brasileiras, permitindo recolocar a "grande política" na ordem do dia.

Palavras-chave: Lutas urbanas. Organização política. Nova hegemonia.

\section{ABSTRACT}

This article seeks to relate the urban social struggles, especially the recent protests in June, with the role of political parties in Brazil today.

1 Mestranda do Programa de Pós-Graduação em Serviço Social (UFSC), na linha de Direitos, Sociedade Civil e Políticas Sociais na América Latina. Graduada em Serviço Social pela Universidade Federal de Santa Catarina. E-mail: bela.ufsc@ gmail.com> 
It aims to demonstrate the importance of political organization for the achievement of rights and for the overcoming of capitalism. For that, we should go back to some theoretical conceptions of party, in a literature review, seeking to bring contributions to think political organization in a consistent way with the particular socio-historical conditions and determinants in our country. If, as the ideas of Lenin and Gramsci, the party should mediate the everyday struggle with the broader struggle to be an agent in the construction of the national-popular will and of the new hegemony, today we are faced with the challenge of overcoming the apathy and angry related to political parties present at the common sense. For this task it is essential to understand this historical moment and its consequences for the class struggle in Brazilian cities, allowing replace the "big politics" on the agenda.

Keywords: Urban struggles. Political organization. New hegemony.

Submetido em 04/09/2013

Aceito em 26/12/2014

\section{INTRODUÇÃO}

As cidades brasileiras passam atualmente por crises evidentes, desde o crescimento da violência, o enorme déficit habitacional associado à valorização e especulação imobiliária até o grau insustentável a que tem chegado a (falta de) mobilidade urbana.

As consequentes lutas sociais em resposta a esses problemas urbanos estão presentes de forma relativamente dispersa em diversos movimentos sociais por moradia, espaços públicos, reforma urbana e mobilidade. Esse último aspecto tem tomado um lugar especial na conjuntura atual.

Por ser uma questão que, num primeiro momento, afeta todas as classes sociais, o tráfego nas cidades proporciona um debate generalizado sobre o tema. As horas gastas para a locomoção de um local a outro causa irritação inclusive nas elites, que se recusam a utilizar transporte coletivo. $O$ discurso presente no pensamento elitista, estendido também à classe média, alega que "os pobres estão tendo acesso à compra de carros, e isto

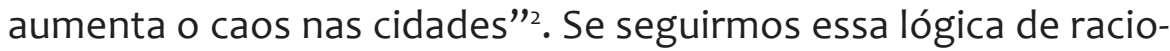

2 A base material para esse discurso tem sido a redução do IPI (Imposto sobre Produtos Industrializados) para automóveis individuais, realizada desde 2008 pelos governos Lula e Dilma, com o suposto objetivo de impulsionar a economia brasileira em um contexto de crise internacional. Esse processo tem gerado aprovação tanto por parte dos setores mais pobres da classe média, 
cínio, então a saída exigida se torna o transporte público para os pobres, e o aumento de vias e infraestrutura urbana que satisfaça os ricos e seus automóveis individuais.

Nesse contexto, é possível observar que as respostas do poder público, em sua maioria, refletem as necessidades apenas dos interesses imediatos da classe dominante, e o transporte coletivo continua a não ser prioridade. As políticas públicas urbanas não priorizam a mobilidade e o transporte público universal, mas os governantes continuam a discursar sobre a necessidade de ampliar vias e construir pontes, ao passo que cedem estímulos à compra de carros como forma de "manter a economia aquecida"3.

Durante o mês de junho de 2013, o Brasil passou por um momento particular em sua história. Milhões de pessoas foram às ruas protestar em todo o país, fato que não se via há décadas. Ainda que com todas as contradições sociais expressas na população manifestante, foi possível observar uma insatisfação geral com a situação atual do Brasil. A ausência de pautas sistematizadas mostrava a vontade de mudanças, aliada à falta de uma análise de conjuntura fundamentada sobre a realidade brasileira.

Um aspecto interessante a ser mencionado é o ponto de partida desse movimento: a luta por transporte público e tarifa zero. O Movimento Passe Livre (MPL) buscou elevar essa pauta como central, mas a insatisfação com a vida nas cidades chegou a tal ponto que houve uma generalização de demandas, culminando numa ausência de foco e na transformação do movimento em uma "grande festa pela democracia", como anunciava a mídia4.

que passaram a ter acesso à compra de carros, como por parte das grandes montadoras automobilísticas, as quais recebem inúmeros incentivos fiscais. Pode-se dizer que esse tipo de medida, ao lado do "Bolsa Família, ampliação do sistema universitário federal com patrocínio das cotas, reajuste do salário mínimo, retomada dos investimentos em infraestrutura, incentivo ao consumo de massas por meio do crédito consignado" (BRAGA, 2010, p. 12), alimenta o "pacto de classes" que respalda o governo federal perante as classes subalternas, ao mesmo tempo que é legitimada pelos setores industriais e financeiros da burguesia.

3 Disponível em: <http://g1.globo.com/platb/mundo-sustentavel/2013/04/01/ reduzir-ipi-de-carro-e-miopia-economica/>. Acesso em: 17 ago. 2013.

4 O papel da mídia nesse processo foi avassalador, merecendo uma análise 
Essa falta de foco ou de pontos centrais - dos quais o movimento não desistiria até a vitória - pode ser explicada pela ausência de direção política capaz de canalizar os anseios das massas hoje no país. Nesse caso, não houve uma estratégia clara presente no imaginário e na ação dos manifestantes. Não havia confiança política em partidos, e mesmo os movimentos sociais organizados não agregaram o conjunto da população.

Por essa razão, pretende-se aqui repensar o papel e a relevância dos partidos políticos e sua influência nas lutas sociais urbanas. Para tanto, voltaremos a algumas concepções teóricas de partido, buscando verificar sua aplicação à realidade atual. É importante ressaltar que não se trata de procurar aplicar fórmulas prontas à realidade brasileira, mas de trazer contribuições para pensar a organização política de forma coerente com as condições e determinantes sócio-históricas particulares em nosso país. Conforme Bogo (2011, p. 96), “criar, a partir da própria realidade, alternativas que desencadeiem os processos revolucionários é o que se pode extrair como ensinamento da dialética".

\section{OS PARTIDOS POLÍTICOS COMO FORMA DE ORGANIZAÇÃO DA CLASSE TRABALHADORA}

“Os filósofos interpretaram o mundo de diferentes
maneiras, porém o que importa é transformá-lo"
(MARX; ENGELS, 2007, p. 539).
"Proletários de todos os países, uni-vos!" (MARX;
ENGELS, 2001, p. 84).

Quando olhamos para as afirmações presentes acima, é possível traçar um paralelo e concluir dois pontos necessários para a transformação da realidade: a) análise da realidade; b) organização política.

Tanto em seus escritos como em sua atividade política, ambos permanentemente imbricados, Marx sempre procurou ressaltar a importância da organização dos trabalhadores para a superação da exploração e opressão capitalistas, tendo

particular. Para um ponto de partida, ver LIMA, Venício. Mídia, rebeldia urbana e crise de representação. In: MARICATO, E. Cidades Rebeldes. São Paulo: Boitempo, 2013. 
como iniciativa a fundação da Associação Internacional dos Trabalhadores, em 1864. Apesar de não haver uma obra inteiramente dedicada à teoria da organização política, observa-se a construção de uma teoria política desde o Manifesto do Partido Comunista, de 1848, e em diversos trechos de Marx e Engels persiste a reivindicação por um partido revolucionário dos trabalhadores. Em um texto de 1850, intitulado "Mensagem do Comitê Central à Liga [dos comunistas]", Marx e Engels (2010, p. 64) afirmam: "É de nosso interesse e é nossa tarefa tornar a revolução permanente até que todas as classes proprietárias em maior ou menor grau tenham sido alijadas do poder, o poder estatal tenha sido conquistado pelo proletariado e a associação dos proletários tenha avançado".

Sobre os embates ocorridos durante as revoluções de 1848, afirmavam que "o partido operário deve atuar do modo mais organizado possível, mais unânime possível e mais autônomo possível, caso não queira ser explorado e atrelado pela burguesia como ocorreu em 1848" (MARX; ENGELS, 2010, p. 59).

De acordo com Braz (2006, p. 27), no Manifesto do Partido Comunista "foram introduzidas as bases conceituais que marcariam definitivamente os rumos dos debates teóricos e políticos no universo socialista e comunista".

Ao enfatizarem nesse texto [no Manifesto] a importância do partido político, Marx e Engels parecem ter descoberto o principal instrumento capaz de promover a passagem da "classe em si" à "classe para si", ou seja, do proletariado como fenômeno objetivo ao proletariado como sujeito coletivo autoconsciente, uma passagem cuja necessidade já fora enunciada por Marx em A miséria da filosofia, escrito em 1847 (COUTINHO apud BRAZ, 2006, p. 28).

Sob a luz da teoria marxista, já no início do século XX, Lenin elaborou concepções mais precisas sobre a organização e funcionamento dos partidos. Com base em suas experiências como dirigente do Partido Operário Social-Democrata Russo (POSDR), assim como na constituição do bolchevismo e na Revolução Russa, Lenin trouxe reflexões para pensar os processos revolucionários e a atuação dos partidos, ressaltando a unidade entre 
teoria e prática: "Sem teoria revolucionária não pode haver também movimento revolucionário" (LENIN, 1979, p. 94). Já no clássico texto Esquerdismo: doença infantil do comunismo, publicado originalmente em 1920, Lenin (2013) ${ }^{5}$ afirma:

De um lado, o bolchevismo surgiu em 1903 fundamentado na mais sólida base da teoria do marxismo. E a justeza dessa teoria revolucionária - e de nenhuma outra - foi demonstrada tanto pela experiência internacional de todo o século XIX como, em particular, pela experiência dos desvios, vacilações, erros e desilusões do pensamento revolucionário na Rússia. [...] Por outro lado, o bolchevismo, surgido sobre essa granítica base teórica, teve uma história prática de quinze anos (1903/1917) sem paralelo no mundo, em virtude de sua riqueza de experiências.

Lukács dedicou-se a escrever um livro sobre Lenin logo após sua morte, em 1924, resgatando a unidade de seu pensamento. Nesse texto, ele afirma que a questão da organização depende do proletariado e do modo como alcança sua própria consciência de classe. Conforme enunciado por Lukács (2012, p. 48), todo aquele que não nega incondicionalmente a função revolucionária do partido deve admitir que essa tomada de consciência "não ocorre por si só, pelo desenvolvimento mecânico das forças econômicas da produção capitalista, e tampouco pelo simples crescimento orgânico da espontaneidade das massas". Ele ressalta que as massas aprendem agindo e na luta se tornam conscientes de seus interesses, além de que, obviamente, não deve ser o partido o responsável por "fazer" uma revolução, mas a função do partido na preparação dos processos revolucionários, junto às massas, "faz dele, ao mesmo tempo e com a mesma intensidade, produtor e produto, pressuposto e resultado dos movimentos revolucionários de massa". Assim, "o ponto fundamental da concepção leniniana do partido é sua função preparatória” (LUKÁCS, 2012, p. 52).

5 As citações concernentes aos textos Esquerdismo: doença infantil do comunismo, de Lenin (2013), e Espontaneidade e direção consciente, de Gramsci (2013), não possuem paginação, pois foram acessadas em páginas da internet, devidamente referenciadas ao final deste trabalho. 
Segundo Lenin, o partido deve ser vanguarda do processo revolucionário e, para isso, tem que estar ligado com a luta cotidiana dos trabalhadores, sendo possível, dessa forma, que a classe trabalhadora desenvolva consciência de seu papel no processo de produção capitalista e da necessidade de construção de uma sociedade sem exploração de uma classe sobre outra. Assim, "o partido deve conhecer verdadeiramente os anseios da classe trabalhadora, pois só assim conseguirá vincular (realizar a mediação) a luta cotidiana com a luta política" (BRAZ, 2006, p. 115). Ainda de acordo com Braz (2006, p. 117),

não há, então, nenhuma oposição entre esponta-
neidade das massas e organização política revolu-
cionária de vanguarda, precisamente porque elas
se complementam, no sentido de que o partido, a
partir do “elemento espontâneo", apoiando-se so-
bre suas iniciativas, amplia-o, o faz ser suplantado
pelo próprio proletariado organizado e consciente,
aproximando-o progressivamente das questões
mais decisivas da luta política revolucionária, da
própria revolução como superação da ordem do
capital através da destruição do poder político de
classe da burguesia.

Nesse sentido, Lenin (1979) soube indicar alguns aspectos para a organização política, como a disciplina e o centralismo democrático. Para ele, o centralismo democrático é uma fusão entre democracia proletária e centralização, que garante a atividade política não mecânica no interior da organização. O partido deve ser estruturado de forma que todos tenham direito a debater e deliberar sobre as linhas, táticas e estratégias políticas, desde o dirigente ao militante de base, assim, uma vez tomadas as decisões e tiradas as linhas de atuação, todos devem segui-las. Lenin aposta na construção da confiança e da camaradagem entre membros do partido, sem abrir mão da hierarquia necessária ao funcionamento político-organizativo. Os dirigentes devem garantir que as linhas sejam implementadas e, em situações de urgência, aplicar as linhas políticas de acordo com os princípios e programa da organização. Isso garante que o partido atue de maneira coesa e coerente, além de negar aos membros com mais influência que suas opiniões se sobressaiam acima das decisões 
do conjunto do partido. "O controle geral (no sentido restrito da palavra) de cada passo dado por um membro do partido em sua carreira política cria um mecanismo que funciona automaticamente, e que assegura o que em biologia se denomina a 'sobrevivência do mais apto"' (LENIN, 1979, p. 177).

Essa estrutura partidária deve garantir a vinculação permanente entre o partido e o cotidiano da classe trabalhadora, favorecendo o desenvolvimento da consciência de classe, na medida em que esta se torna protagonista na elaboração de estratégias políticas rumo à sua emancipação política, social, econômica, cultural, enfim, humana. Conforme Lenin (2013), "o partido revolucionário do proletariado não será merecedor desse nome enquanto não souber ligar os líderes à classe e às massas num todo único e indissolúvel".

No que se refere à relação entre partido e demais organizações da classe trabalhadora, Lenin (apud BRAZ, 2006, p. 114) afirma:

Havia uma clara distinção dos objetivos (e das formas de organização) entre partido e organizações operárias (equivalentes ao que conhecemos como sindicatos). Estas se vinculam a um nível mais imediato da luta de classes, envolvendo o conjunto de particularidades (e de interesses sociais) atuantes na luta, evidenciadas nas lutas econômicas que os operários travam nas fábricas. Seu foco político de atuação limita-se à defesa de interesses particulares diversos, podendo, através de permanentes "revelações políticas", ser relacionados à luta política mais ampla, de caráter universal. Essa última caberia ao partido (organizações revolucionárias), que deveria ter o papel simultâneo de promover as "revelações políticas", de realizar o processo constante de "educação para a atividade revolucionária" e, ainda, de provocar a agitação político-ideológica das massas em todos os aspectos da vida social, para além da "agitação política no terreno econômico".

Dentro desse contexto, pode-se relacionar esse aspecto da obra de Lenin com o que Antonio Gramsci ${ }^{6}$ classifica como

6 Não é intuito deste trabalho tratar as diferenças conceituais entre Lenin e 
dois momentos constitutivos da "catarse" (COUTINHO, 2012, p. 91): econômico-corporativo, "do nível mais imediato da luta de classes"; e ético-político, "a luta política mais ampla, de caráter universal”. É importante ressaltar que não há uma separação mecânica entre os dois momentos, mas sim uma relação processual e dialética, associada às condições históricas e contraditórias de cada realidade social.

Gramsci desenvolveu atentamente concepções sobre o partido político, complementando e revigorando as elaborações marxistas até o seu tempo. Com uma clareza teórica e uma análise de realidade advinda também de sua militância política, a teoria de Gramsci traz diversas contribuições deveras importantes para avançar na superação do capitalismo.

O moderno príncipe, o mito-príncipe não pode ser uma pessoa real, um indivíduo concreto, só pode ser um organismo; um elemento complexo de sociedade no qual já tenha tido início a concretização de uma vontade coletiva reconhecida e afirmada parcialmente na ação. Este organismo já está dado pelo desenvolvimento histórico e é o partido político a primeira célula na qual se sintetizam germes de vontade coletiva que tendem a se tornar universais e totais (GRAMSCl, 2003, p. 16).

O partido, de acordo com essa concepção, existe e se mantém na sociedade civil como um aparelho privado de hegemonia. Para Gramsci, através desses aparelhos - partido, sindicato, escola, mídia, igreja -, a classe trabalhadora pode disputar a hegemonia com a classe dominante, conforme sua capacidade de elaborar a vontade coletiva nacional-popular. Essa formação da vontade coletiva é chamada por Gramsci de "reforma intelectual e moral”, e, segundo Coutinho (2012, p. 172), "o partido não luta apenas por uma renovação política, econômica e social, mas também por uma revolução cultural, pela criação e desenvolvimento de uma nova cultura".

Nesse sentido, buscando superar a dicotomia entre reforma e revolução, Gramsci (2003, p. 19) questiona:

Gramsci, mas sim buscar os pontos fundamentais que os aproximam na teoria sobre os partidos políticos. 
Pode haver reforma cultural, ou seja, elevação civil das camadas mais baixas da sociedade, sem uma anterior reforma econômica e uma modificação na posição social e no mundo econômico? É por isso que uma reforma intelectual e moral não pode deixar de estar ligada a um programa de reforma econômica.

Com o objetivo de realização da reforma intelectual e moral, Gramsci dá especial importância ao papel dos intelectuais, ressaltando que estes podem estar vinculados a um projeto de classe, caracterizando-os como intelectuais orgânicos na difusão de uma nova cultura. Assim, é fundamental que a classe trabalhadora tenha intelectuais orgânicos engajados na construção de seu projeto de classe e, portanto, de uma nova hegemonia7. Nesse sentido, o partido passa a ser o "intelectual coletivo". Segundo Coutinho (2012), para Gramsci, todos os membros do partido devem ser considerados intelectuais, devido à função dirigente, organizativa e educativa que exercem.

Guardando grandes similaridades com a teoria de Lenin, um aspecto fundamental do partido na concepção gramsciana deve ser dar direção consciente ao espontaneísmo, ou seja, em momentos de mobilização espontânea da classe trabalhadora o partido deve articular as lutas em uma síntese capaz de universalizar tais movimentos. No texto Espontaneidade e direção consciente, de 1931, Gramsci (2013) afirma que "descuidar - e mais ainda, depreciar - os movimentos chamados espontâneos, ou seja, renunciar a dar-lhes uma direção consciente, a elevá-los a um plano superior inserindo-os na política, pode ter consequências graves”.

Conforme explicitado por Duriguetto (2007, p. 65), “eis a tarefa central que cabe ao partido político: transformar as massas em sujeitos ativos, organizados, e direcionar o conjunto desagregado e espontâneo das ideologias a uma direção consciente". De acordo com a referida autora, é nesse âmbito que se efetiva o

\footnotetext{
7 Segundo Martins e Neves (2010, p. 24), “o conceito de hegemonia na acepção gramsciana designa um complexo processo de relações vinculadas ao exercício do poder nas sociedades de classes, que se materializa a partir de uma concepção de mundo e da prática política de uma classe ou fração de classe. O exercício da hegemonia é, para Gramsci (1999), sempre uma relação pedagógica que busca subordinar em termos morais e intelectuais grupos sociais inteiros por meio da persuasão e da educação".
} 
momento de articulação entre objetividade e subjetividade. "Em Gramsci, a esfera da política é a esfera dos processos de superação de uma práxis de mera recepção passiva, imediata e subalterna da vida social para uma forma de práxis ativa, propositiva e que se orienta para a universalidade" (DURIGUETTO, 2007, p. 65).

Quanto à estrutura interna do partido, Gramsci aposta em três grupos de elementos: 1) elemento difuso de homens comuns ou médios, caracterizados mais pela disciplina e fidelidade do que por seu espírito criativo e organizativo; 2) elemento principal de coesão, que dirige, organiza e centraliza o partido; 3) elemento intermediário, que serve de ligação entre os dois outros, apresentando traços de um e de outro (BOGO, 2011; COUTINHO, 2012). No entanto, Coutinho (2012) denota que essa não é uma divisão imutável, mas que o próprio partido deve trabalhar para eliminar essas diferenças. Além disso, não se pode esquecer de que toda forma está necessariamente imbricada a um conteúdo e que cabe a cada momento histórico e realidade específica traçar as melhores estruturas (formas) para o caráter que deseja dar aos seus partidos (conteúdos).

De todo esse arcabouço teórico acerca do partido político, de Marx, Lenin e Gramsci a seus diversos intérpretes intelectuais orgânicos e militantes, pode-se concluir que é fundamental que a classe trabalhadora se organize coletivamente tanto para a conquista de direitos imediatos como para a superação do capitalismo por uma sociedade sem classes. O partido político tem um papel imprescindível nesse processo de mediação entre os interesses imediatos e a luta mais ampla. Assim, deve-se questionar se existe hoje um partido capaz de realizar essa mediação na realidade brasileira. "O político em ato é um criador, um suscitador, mas não cria a partir do nada nem se move na vazia agitação de seus desejos e sonhos. Toma como base a realidade efetiva: mas o que é esta realidade efetiva?" (GRAMSCI, 2003, p. 35, grifo nosso).

\section{AS LUTAS URBANAS E A POLÍTICA NA ATUALIDADE}

Marini (2008, p. 27), em uma análise sobre a democracia na América Latina, afirma que, "num mundo dividido em grupos e classes, a participação direta como cidadão na sociedade e no 
Estado constitui um mero ideal, só podendo tornar-se efetiva mediante sua participação num partido político".

No entanto, o que se vê na realidade brasileira atual, em particular durante as manifestações ocorridas em todo o país em junho de 2013, é uma negação dos partidos políticos e a busca por uma suposta democracia em que os partidos não são bem-vindos. Torna-se, então, tarefa imprescindível entender esse momento histórico e suas consequências para a luta de classes nas grandes cidades brasileiras. Não há pretensão de esgotar esse tema neste breve trabalho, mas apenas apontar elementos que auxiliem na construção de uma análise sobre o momento atual ${ }^{8}$.

Oliveira (2010), em um estudo de 2007 sobre a reeleição de Lula, buscou realizar uma análise de conjuntura a respeito daquele momento. Um dos aspectos observados por ele foi a quantidade de coligações e coalizões que se formaram no período eleitoral, sem nenhum critério ideológico: "Siglas de suposta orientação ideológica oposta uniram-se indiscriminadamente com toda espécie de agrupamentos". Oliveira conclui que essa falta de consistência confirma a irrelevância da política partidária no capitalismo contemporâneo: "Os partidos representam pouco, e a política está centrada sobretudo nas personalidades" (OLIVEIRA, 2010, p. 22).

$\mathrm{O}$ autor menciona ainda que Lula distanciou-se do PT e somente recorreu ao partido quando a reeleição esteve ameaçada. Para Oliveira (2010), Lula não possuía objetivos porque não tinha inimigos de classe. Aí se inicia sua tese fundamental: a de que o Brasil passa pela construção de uma "hegemonia às avessas" , em que as classes subalternas chegam ao poder, mas sem projeto próprio, por isso governam de acordo com o projeto hegemônico das classes dominantes. Com a figura de Lula como presidente, cria-se a ideia de que foi destruído o preconceito de classe. No entanto, Lula "despolitiza a questão da pobreza e da

8 A Boitempo Editorial publicou, já em julho de 2013, um compilado de textos de diversos autores brasileiros e estrangeiros sobre as manifestações de junho. Intitulado de Cidades Rebeldes, o livro será utilizado aqui como contribuição fundamental de autores que prontamente se dispuseram a pensar essa realidade.

9 Esse termo cunhado por Francisco de Oliveira deu origem ao livro Hegemonia às avessas, também editado pela Boitempo em 2010. 
desigualdade", transformando-as em problema de administração. Com a cooptação dos movimentos sociais e organizações da sociedade civil já no primeiro mandato - processo que Gramsci denomina como transformismo -, "os movimentos sociais praticamente desapareceram da agenda política” (OLIVEIRA, 2010, p. 25).

Oliveira (2010) declara, então, que estamos diante de um fenômeno novo que exige novas reflexões, pois esse processo não se parece com qualquer das práticas de dominação exercidas na história do Brasil.

Nos termos de Marx e Engels, da equação "força + consentimento" que forma a hegemonia desaparece o elemento "força". E o consentimento se transforma em seu avesso: não são mais os dominados que consentem em sua própria exploração; são os dominantes - os capitalistas e o capital, explicite-se - que consentem em ser politicamente conduzidos pelos dominados, com a condição de que a "direção moral" não questione a forma da exploração capitalista (OLIVEIRA, 2010, p. 27).

Coutinho (2010), ao comentar o termo "hegemonia às avessas", afirma preferir falar em "hegemonia da pequena política".

Gramsci (2003, p. 21), em Cadernos do Cárcere, caracteriza a grande política como "as questões ligadas à fundação de novos Estados, à luta pela destruição, pela defesa pela conservação de determinadas estruturas orgânicas econômico-sociais", enquanto que a pequena política "compreende as questões parciais e cotidianas que se apresentam no interior de uma estrutura já estabelecida em decorrência de lutas pela predominância entre as diversas frações de uma mesma classe política". Para ele, trata-se da política do dia a dia, política parlamentar etc. e ressalta que faz parte da grande política tentar "reduzir tudo a pequena política".

Desse modo, Coutinho (2010, p. 32) baseia sua fundamentação na categoria gramsciana da pequena política, explicitando que "existe hegemonia da pequena política quando a política deixa de ser pensada como arena de luta por diferentes propostas de sociedade e passa, portanto, a ser vista como um terreno 
alheio à vida cotidiana dos indivíduos, como simples administração do existente". Assim, a ideologia dominante é incorporada pelas massas através de um consenso passivo, fazendo com que estas deixem de organizar-se em partidos e outros organismos da sociedade civil, pois aceitam o existente como natural e imutável. Nesse âmbito, Coutinho (2010, p. 43) afirma que "o principal desafio da esquerda hoje é recolocar a grande política na ordem do dia, único modo de quebrar a hegemonia da pequena política e, portanto, do capitalismo em sua forma atual, a da servidão financeira" ${ }^{\prime \prime}$.

Nesse contexto de afastamento das massas da grande política, as manifestações de junho foram uma surpresa para todos, visto o número exorbitante de pessoas que foram às ruas em todo o país, nas pequenas, médias e grandes cidades. Seria esse o momento da volta da grande política? A população voltou a ter consciência de seu papel na organização coletiva? Qual o papel dos partidos políticos nesse processo?

Serão trazidas aqui sínteses de diversos autores que ousaram escrever sobre esse momento político, no intuito de formular respostas às questões propostas acima.

Segundo Maricato (2013), é impossível dissociar as principais razões, objetivas e subjetivas, desses protestos da condição atual das cidades com todas as suas contradições e desigualdades. $\mathrm{O}$ boom imobiliário de enormes proporções nas grandes cidades e o esquecimento da pauta da reforma urbana nas agendas políticas têm aumentado a segregação socioespacial e piorado consideravelmente a condição de vida nos centros urbanos.

Conforme dados trazidos pela autora, "em São Paulo, o preço dos imóveis sofreu aumento de 153\% entre 2009 e 2012; no Rio de Janeiro, o aumento foi de $184 \%$. A terra urbana permaneceu refém dos interesses do capital imobiliário" (MARICATO, 2013, p. 23-24). Ela aponta ainda que "é com a condição dos transportes que as cidades acabam cobrando mais sacrifícios por parte de

10 Sobre a servidão financeira, ver PAULANI, Leda. Capitalismo financeiro, Estado de emergência econômico e hegemonia às avessas no Brasil. In: OLIVEIRA, Francisco; BRAGA, Ruy; RIZEK, Cibele (Org.). Hegemonia às avessas. São Paulo: Boitempo, 2010. 
seus moradores", pois, embora a piora de mobilidade seja geral, são as camadas de rendas mais baixas que pagam com maior imobilidade. Maricato (2013) mostra que o número de carros nas grandes metrópoles duplicou na última década e que o governo brasileiro cedeu mais subsídios para a circulação de automóveis (incluindo combustível e outros itens) do que para o transporte coletivo, conforme apontado na introdução deste trabalho.

Harvey (2013, p. 30), ao comentar as manifestações ocorridas, explicita que a vida nas cidades tende ao conflito social e que devemos nos perguntar se os resultados desse conflito são criativos ou destrutivos. "Normalmente são ambos: a cidade tem sido por muito tempo um epicentro de criatividade destrutiva". Ele conclui que o direito à cidade não é um presente e tem de ser tomado pelo movimento político.

Para seguir tal recomendação, faz-se necessário questionar como surgiu esse movimento e como é possível dar consequência à espontaneidade que foi às ruas. Para tanto, é fundamental entender quem são essas pessoas, quais suas experiências, seus objetivos e suas compreensões sobre o mundo.

Vainer (2013, p. 37) relaciona o surgimento dos protestos com os megaeventos esportivos como ponto culminante: “Megaeventos, meganegócios, megaprotestos". Segundo o autor, não há como não reconhecer a conexão entre as manifestações ocorridas e os investimentos urbanos associados à Copa do Mundo de 2014 e aos Jogos Olímpicos de 2016.

Sob a égide do Consenso de Washington, a cidade passa a ser investida como espaço direto e sem mediações da valorização e financeirização do capital. Concebidas enquanto empresas em concorrência umas com as outras pela atração de capitais (e eventos, é óbvio), as cidades e os territórios se oferecem ao mercado global entregando a capitais cada vez mais móveis (foot loose) recursos públicos (subsídios, terras, isenções) (VAINER, 2013, p. 37)".

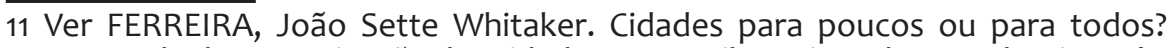
Impasses da democratização das cidades no Brasil e o risco de um urbanismo às avessas. In: OLIVEIRA, Francisco; BRAGA, Ruy; RIZEK, Cibele (Org.). Hegemonia às avessas. São Paulo: Boitempo, 2010. 
Em uma análise otimista, Vainer (2013) destaca que os movimentos urbanos - tais quais Movimento Passe Livre, Movimento dos Trabalhadores Sem Teto, Central de Movimentos Populares, entre outros - trazem à tona a resistência frente a essa mercantilização da cidade neoliberal, reivindicando outra cidade, outro espaço público.

Já na análise de lasi (2013, p. 46), "o acordo com a burguesia realizado na cúpula do governo brasileiro produziu na base social uma reversão na consciência de classe e uma inflexão conservadora no senso comum". Esse autor demonstra que, quando explodem as contradições no campo até então inerte, manifestam-se elementos do bom senso contra a ordem, ao passo que surgem representações de conteúdos conservadores e preocupantes do senso comum - como o nacionalismo exacerbado, o antipartidarismo, a retomada da extrema direita. Ainda que com essas contradições, lasi (2013, p. 46) aponta que "a repressão aos jovens e a prepotência dos governantes funcionaram como catalisador das contradições que germinavam sob a aparência de que tudo corria bem em nosso país".

No entanto, essa polarização ocorrida entre o senso comum e as organizações políticas merece o foco do esboço que se pretende traçar aqui. Se, conforme as concepções de Lenin e Gramsci, o partido deve ser a mediação entre a luta cotidiana e a luta mais ampla, agente da construção da vontade nacional-popular e de uma nova hegemonia, por que não somente não foi possível fazê-lo, como ainda foi repudiado pelo senso comum presente nas manifestações?

Como vimos, a ação espontânea das massas não é um fenômeno novo. O que deve ser inteiramente novo é a análise das condições históricas, sociais, econômicas, políticas e culturais pelas quais passamos atualmente.

Se a organização partidária deixa de elaborar as suas próprias ideias e apenas copia formulações feitas em outros contextos, é claro que a estrutura organizativa repetirá os métodos e o pensamento formulados para determinada realidade, mas aplicados sobre outra, como se vivesse no tempo de seus antepassados. Isso é um equívoco. As experiências 
servem como referências que marcam possibilidades, mas não podem ser tomadas como receitas imutáveis. Sem a dinamicidade das contradições específicas, a revolução não nasce, e se nasce não se alimenta e morre (BOGO, 2011, p. 97).

Conforme declarado por Sakamoto (2013), a esquerda não pode ter medo do novo, pois somente assim pode captar as mudanças na realidade sobre a qual atua. $O$ autor expõe que esses jovens que foram às ruas utilizam novas formas de articulação, como o exemplo das redes sociais. Grande parte deles está descontente e não sabe o que quer, mas sabe o que não quer. Por essa razão, muitos abraçaram bandeiras da direita com discursos fáceis, como os "sem partido".

\begin{abstract}
Um gigantesco grupo formado principalmente de jovens, precariamente informado, desaguou subitamente nas manifestações de rua, sem nenhuma formação política, mas com muita raiva e indignação, abraçando a bandeira das manifestações. A revolta desses contra quem portava uma bandeira não foi necessariamente contra o sistema partidário, mas sim contra as instituições tradicionais que representam a autoridade como um todo (SAKAMOTO, 2013, p. 98).
\end{abstract}

No entanto, de acordo com Sakamoto (2013, p. 98), “ignoravam que a livre associação em partidos e a livre expressão são direitos humanos". Secco (2013) traz dados os quais revelam que, em São Paulo, 84\% dos manifestantes no dia 17 de junho não tinham preferência partidária, $71 \%$ participavam pela primeira vez de um protesto e $53 \%$ tinham menos de 25 anos. Esse autor relata que a taxa de apartidarismo no Brasil sempre foi alta, devido a nossa construção sócio-histórica, mas o problema que se coloca agora é o antipartidarismo. "Os manifestantes virtuais não canalizam seu descontentamento pela representação política. Assim, ela se reduz a uma crítica generalizada dos próprios políticos profissionais, mas não do modo de produção da política, enredando-se num emaranhado abstrato" (SECCO, 2013, p. 72).

Procurar entender os condicionantes externos desse repúdio às organizações políticas e aos partidos indica que não podemos eximi-los da autocrítica, da avaliação de suas teorias, 
práticas e linhas de atuação. Uma das críticas mais comuns aos partidos de esquerda hoje é o aparelhamento que supostamente fazem aos movimentos sociais. Aparelhamento significa utilizar as ações de determinados movimentos sociais para a autopromoção e autoconstrução. Por essa razão, movimentos anarquistas e adeptos da autogestão costumam negar a presença de bandeiras e demais símbolos partidários durante atos e protestos de movimentos específicos. Por outro lado, existem também grupos fascistas e de direita que negam os partidos de esquerda por questões ideológicas conscientes. No caso das manifestações de junho, o nível de agressão aos militantes organizados chegou a tal ponto que tanto anarquistas quanto socialistas e comunistas uniram-se buscando a autoproteção.

Marini (2008) faz uma ressalva quanto à relação entre os partidos e organizações e os movimentos sociais, quando menciona que estes não representam entidades antagônicas, mas são modos de articulação de diferentes esferas da vida real, que tratam de diferentes dimensões e instâncias da participação em sociedade. Assim, "contrapô-los ou hierarquizá-los e subordiná-los uns aos outros, com propósitos instrumentalistas, conduz o homem e sua prática social à desintegração". O autor continua dizendo que, por outro lado, "assumi-los como elementos interdependentes e harmônicos leva à recuperação do homem integral em sua diversidade e riqueza, permitindo aspirar à construção de uma sociedade lhe proporcione amplo espaço para o seu desenvolvimento" (MARINI, 2008, p. 27).

Marini (2008) lembra, ainda, que a maior responsabilidade nesse processo de reorganização dos partidos de esquerda é da própria esquerda, a qual deve refletir sobre suas experiências e delas tirar as lições necessárias para o avanço da ação política revolucionária. Além disso, deve abrir-se sem preconceito à compreensão do desenvolvimento do movimento popular, com todas suas contradições. Segundo Marini (2008, p. 27), "o outro caminho, da discussão meramente doutrinária, que ela tantas vezes se vê tentada a trilhar, não lhe abre perspectivas reais de desenvolvimento". 


\section{CONSIDERAÇÕES FINAIS}

O papel do partido revolucionário deve ser entender os anseios das massas e trabalhar conjuntamente com elas para elevar sua consciência através da luta política, como foi tratado no primeiro item deste trabalho. Pode-se arriscar afirmar que, durante as manifestações de junho, isso não aconteceu, já que não há partido político hoje que represente os anseios, demandas e desejos das massas urbanas. Não se compartilha aqui, de maneira nenhuma, da análise de que os partidos não são mais necessários, pois não existem mais classes sociais no Brasil contemporâneo. O que se define, isso sim, de acordo com os rumos tomados pelas manifestações, é que os partidos possuem desafios ainda maiores pela frente. Sem uma análise precisa das classes sociais, da conjuntura política, e sem uma estratégia pelo socialismo - e não apenas pela autoconstrução partidária -, não será possível delinear as tarefas que as organizações dos trabaIhadores devem assumir na luta por conquistas e direitos sociais se não houver uma articulação dessas organizações com a luta política mais ampla pela superação do capitalismo.

Para seguir a indicação de Coutinho de "recolocar a grande política na ordem do dia", a esquerda precisa não só repensar suas práticas, como também munir-se de análises teóricas, da realidade atual e das correlações de forças no Brasil. As alianças dos setores dominantes com os mais pobres, nos âmbitos político, econômico e ideológico, têm complexificado as relações sociais e tornado um desafio ainda maior definir seus desdobramentos para a organização política. Por esse motivo, compreender o pacto de classes realizado no governo Lula e a suposta ampliação da classe média deve ser uma tarefa da esquerda brasileira atualmente.

Nesse sentido, não se pode deixar de resgatar experiências históricas e concepções teóricas que tanto podem nos ajudar a compreender nossa realidade e agir para transformá-la. No entanto, essa fundamentação deve ser sempre nosso ponto de partida, rumo ao ponto de chegada travado na ação cotidiana. Conforme lembrado por Lenin (2013), "é preciso compreender perfeitamente que esse centro dirigente não pode, de modo 
algum, ser formado segundo normas táticas estereotipadas de luta, mecanicamente igualadas, idênticas". A partir daí, ficam indicados os desafios.

\section{REFERÊNCIAS}

BOGO, Ademar. Organização política e política de quadros. São Paulo: Expressão Popular, 2011.

BRAGA, Ruy. Apresentação. In: OLIVEIRA, Francisco; BRAGA, Ruy; RIZEK, Cibele (Org.). Hegemonia às avessas. São Paulo: Boitempo, 2010. p. 7-14.

BRAZ, Marcelo. Partido Proletário e Revolução: sua problemática no século XX. Tese (Doutorado em Serviço Social) - Programa de Pós-graduação em Serviço Social, Universidade Federal do Rio de Janeiro, Rio de Janeiro, 2006.

COUTINHO, Carlos Nelson. A hegemonia da pequena política. In: OLIVEIRA, Francisco; BRAGA, Ruy; RIZEK, Cibele (Org.). Hegemonia às avessas. São Paulo: Boitempo, 2010. p. 29-46.

COUTINHO, Carlos Nelson. Gramsci: um estudo sobre seu pensamento político. 4. ed. Rio de Janeiro: Civilização Brasileira, 2012.

DURIGUETTO, Maria Lúcia. Sociedade civil e democracia. São Paulo: Cortez, 2007.

GRAMSCI, Antonio. Cadernos do cárcere. Tradução de Carlos Nelson Coutinho com a colaboração de Luiz Sergio Henriques e Marco Aurélio Nogueira. Rio de Janeiro: Civilização Brasileira, 2003.

GRAMSCI, Antonio. Espontaneidade e direção consciente. Disponível em: <http://gramsci-brasil.blogspot.com.br/2007/10/ espontaneidade-e-direo-consciente.html>. Acesso em: 08 ago. 2013.

HARVEY, David. A liberdade da cidade. In: MARICATO, E. et al. Cidades Rebeldes. São Paulo: Boitempo, 2013. p. 27-34. 
IASI, Mauro. A rebelião, a cidade e a consciência. In: MARICATO, E. et al. Cidades Rebeldes. São Paulo: Boitempo, 2013. p. 41-46.

LENIN, Vladimir. Que fazer? In: LENIN, Vladimir. Obras escolhidas. Tomo 1. São Paulo: Alfa-Omega, 1979. p. 94-177.

LENIN, Vladimir. Esquerdismo: doença infantil do comunismo. Disponível em: <http://www.marxists.org/portugues/lenin/1920/ esquerdismo/index.htm>. Acesso em: 20 ago. 2013.

LUKÁCS, Gyorgy. Lenin. São Paulo: Boitempo, 2012.

MARICATO, Ermínia. É a questão urbana, estúpido! In: MARICATO, E. et al. Cidades Rebeldes. São Paulo: Boitempo, 2013. p. 19-26.

MARINI, Ruy Mauro. A luta pela democracia. In: COLEÇÃO Cadernos de Pensamento Crítico Latino-americano. v. 1. São Paulo: CLACSO/Expressão Popular, setembro de 2008. p. 20-34.

MARTINS, André Silva; NEVES, Lúcia Maria Wanderley. A nova pedagogia da hegemonia e a formação/atuação de seus intelectuais orgânicos. In: NEVES, Lúcia Maria Wanderley (Org.). Direita para o social e esquerda para o capital. São Paulo: Xamã, 2010. p. 23-38.

MARX, Karl; ENGELS, Friedrich. A Ideologia Alemã. São Paulo: Boitempo, 2007.

MARX, Karl; ENGELS, Friedrich. Manifesto do Partido Comunista. Porto Alegre: L\&PM Pocket, 2001.

MARX, Karl; ENGELS, Friedrich. Mensagem do Comitê Central à Liga [dos comunistas]. In: MARX, K.; ENGELS, F. Luta de classes na Alemanha. São Paulo: Boitempo, 2010. p. 57-76.

OLIVEIRA, Francisco. Hegemonia às avessas. In: OLIVEIRA, Francisco; BRAGA, Ruy; RIZEK, Cibele (Org.). Hegemonia às avessas. São Paulo: Boitempo, 2010. p. 21-28. 
SAKAMOTO, Leonardo. Em São Paulo, o Facebook e o Twitter foram às ruas. In: MARICATO, E. et al. Cidades Rebeldes. São Paulo: Boitempo, 2013. p. 95-100.

SECCO, Lincoln. As jornadas de junho. In: MARICATO, E. et al. Cidades Rebeldes. São Paulo: Boitempo, 2013. p. 71-78.

VAINER, Carlos. Quando a cidade vai às ruas. In: MARICATO, E. et al. Cidades Rebeldes. São Paulo: Boitempo, 2013. p. 35-40. 